\title{
STUDI HASIL INDEKS ERITROSIT PADA PENDERITA STROKE ISKEMIK DAN STROKE HEMORAGIK
}

\author{
Syahida Djasang ${ }^{1}$, Nurul Hikma ${ }^{2}$ \\ ${ }^{1,2}$ Jurusan Analis Kesehatan Poltekkes Makassar \\ Koresponden :: syahida.djasang@gmail.com
}

\begin{abstract}
ABSTRAK
Stroke adalah penyakit yang ditandai oleh penurunan fungsi otak yang tejadi karena sumbatan, penyempitan, pecahnya pembuluh darah dan terhentinya alirah darah ke otak. Hemoglobin, hematokrit dan eritrosit berperan penting terhadap derajat klinis stroke karena terkait dengan oksigenasi di jaringan otak yang mengalami infark. Salah satu yang berperan penting dalam proses oksigenasi dalam aliran darah ialah eritrosit. Berkurangnya hemoglobin dalam darah akan menyebabkan kurangnya suplai oksigen ke otak. Penelitian ini bertujuan untuk mengetahui gambaran hasil indeks eritrosit pada penderita stroke iskemik dan stroke hemoragik. Penelitian ini dilaksanakan di Laboratorium Hematologi Rumah Sakit dr. Wahidin Sudirohusodo Makassar pada bulan Maret sampai dengan Mei 2018. Jenis penelitian ini adalah penelitian descripitive. Analisa data secara analitik dilakukan uji labotaorium untuk mengetahui gambaran hasil indeks eritrosit pada penderita stroke iskemik dan stroke hemoragik. Hasil penelitian yang diperoleh pada penderita stroke iskemik didapatkan nilai $\mathrm{MCV}, \mathrm{MCH}$ dan $\mathrm{MCHC}$ yang rendah, Terdapat 5 penderita dengan nilai MCV rendah, 6 penderita dengan nilai $\mathrm{MCH}$ rendah dan 8 penderita dengan dilai $\mathrm{MCHC}$ rendah. Pada penderita stroke hemoragik didapatkan nilai $\mathrm{MCV}, \mathrm{MCH}$ dan $\mathrm{MCHC}$ yang rendah, Terdapat 1 penderita dengan nilai $\mathrm{MCV}$ rendah, 5 penderita dengan nilai $\mathrm{MCH}$ rendah dan 8 penderita dengan dilai $\mathrm{MCHC}$ rendah
\end{abstract}

Kata Kunci : Stroke, Indeks eritrosit

\section{PENDAHULUAN}

Stroke adalah penyakit yang ditandai oleh penurunan fungsi otak, yang terjadi karena sumbatan, penyempitan, pecahnya pembuluh darah dan terhentinya aliran darah ke otak yang berlangsung selama 24 jam atau lebih atau berakhir dengan kematian. Stroke bukanlah penyakit asing bagi masyarakat Indonesia. Hal ini disebabkan oleh cukup tingginya insidensi kasus stroke yang terjadi dimasyarakat dan cenderung meningkat setiap tahunnya. Insidensi stroke melintasi batas-batas sosioekonomi, jenis kelamin manusia. (Wahyu, 2009).

Insiden stroke bervariasi antar negara dan tempat. Menurut hasil penelitian yang dikoordinasi oleh WHO, dari 16 pusat riset di 12 negara maju dan berkembang antara Mei 1971 sampai Desember 1974 memperlihatkan bahwa insiden stroke yang paling tinggi adalah di Ahita (Jepang) yaitu 287 per 100.000 populasi per tahun, sedang yang terendah di Ibadan (Nigeria) sebesar 
Jurnal Media Analis Kesehatan, Vol. 9, No.2, November 2018

http://journal.poltekkes-mks.ac.id/ojs2/index.php/mediaanalis

e-ISSN : 2621-9557

p-ISSN : 2087-1333

150 per 100.000 populasi pertahun. Clifford Rose dari Inggris memperkirakan insiden stroke dikebanyakan negara adalah sebesar 200 per 100.000 populasi per tahun. Insiden infark otak dan perdarahan intra serebral meningkat sesuai dengan pertambahan umur. (Bustan, 2007)

Menurut hasil Riskesdas Provinsi Sulawesi Selatan tahun 2013 Prevalensi penyakit stroke pada kelompok yang didiagnosis atau gejala meningkat seiring bertambahnya umur, tertinggi pada umur $\geq 75$ tahun $(38,5 \%$ dan $69,1 \%)$. Prevalensi stroke yang di diagnosis maupun yang di diagnosis berdasarkan gejala pada laki-laki lebih tinggi dari perempuan. Terdapat stroke penderita lama sebanyak 1.811 kasus dan penderita baru 3.512 kasusdengan 160 kematian.

Ada beberapa faktor risiko yang memudahkan timbulnya stroke diantaranya hipertensi, diabetes mellitus, merokok dan alcohol. Kehilangan suplai oksigen secara mendadak kejaringan otak selain glukosa merupakan langkah pertama dan utama dalam pathogenesis stroke. Fokus infark di otak dapat diselamatkan dengan kemampuan darah membawa oksigen yang cukup ke otak. Salah satu hal yang terlibat dalam proses oksigenasi otak selain adanya sumbatan pada pembuluh darah otak adalah ada tidaknya kondisi kadar $\mathrm{Hb}$ yang rendah pada penderita stroke. Beberapa studi di Eropa dan Amerika menunjukkan adanya hubungan Hemoglobin dan Hematokrit dengan derajat klinis pasien stroke iskemik dan stroke hemoragik. Penelitian terbaru juga menunjukkan bahwa sekitar satu dari lima pasien stroke disertai dengan anemia dilaporkan mempunyai hubungan yang erat dengan derajat klinis penderita stroke. (Basir dkk, 2014).

Menurut Adhim dalam penelitiannya tahun 2013 perubahan hemostasis darah karena berbagai sebab seperti kenaikan hematokrit dapat meningkatkan kemungkinan terjadinya stroke. Kadar hematokrit yang tinggi menyebabkan meningkatnya viskositas darah sehingga berakibat turunnya aliran darah dalam otak. Meskipun peningkatan viskositas darah tidak hanya disebabkan oleh peningkatan hematokrit, namun bila kadar hematokrit melampaui 46\% maka viskositas darah akan meningkat dengan tajam.

Dalam pemeriksaan Indeks eritrosit biasanya digunakan untuk melihat jenis anemia. Indeks eritrosit terdiri dari MCV (volume eritrosit rerata), dan $\mathrm{MCH}$ (hemoglobin eritrosit rerata). Nilai indeks eritrosit di dapat dari hasil pemeriksaan hemoglobin, hematokrit dan jumlah eritrosit. (Gandoseobrata R, 2013). Indeks eritrosit dapat ditetapkan dengan dua metode yaitu manual dan automatic menggunakan Hematologi Analyser. Untuk menghitung indeks eritrosit secara manual diperlukan nilai kadar hemoglobin, hematokrit dan hitung eritrosit. Derajat klinis dari penderita stroke sangat bervariasi tergantung dari berat ringannya stroke yang diderita dan cepat tidaknya seorang pasien mendapatkan pertolongan.

Hasil penelitian yang dilaksanakan Adhim (2013) kepada 110 penderita RSUD Dr. Moewardi didapatkan perbedaan hitung 
Jurnal Media Analis Kesehatan, Vol. 9, No.2, November 2018

http://journal.poltekkes-mks.ac.id/ojs2/index.php/mediaanalis

e-ISSN : 2621-9557

p-ISSN : 2087-1333

hematokrit pada stroke iskemik dan stroke hemoragik. Hasil tersebut menunjukkan rerata hitung hematokrit stroke hemoragik lebih rendah dari pada stroke iskemik. Dalam kasus ini, penyakit stroke mempunyai hubungan dengan indeks eritrosit yaitu kadar hemoglobin, kadar hematokrit dan jumlah eritrosit. Dimana dalam beberapa penelitian, pemeriksaan indeks eritrosit digunakan untuk menentukan jenis anemia.

Dari Uraian diatas peneliti telah melakukan penelitian mengenai gambaran hasil indeks eritrosit pada penderita stroke iskemik dan stroke hemoragik

\section{METODE}

Jenis penelitian ini adalah penelitian deskriptif yakni melakukan uji laboratorium untuk melihat gambaran hasil indeks eritrosit pada penderita stroke iskemik dengan penderita stroke hemoragik. Penelitian dilakukan di Laboratorium RSUP Dr. Wahidin Sudirohhusodo pada bulan Maret-Mei 2018

Populasi dalam penelitian ini adalah semua penderita stroke di Rumah Sakit dr. Wahidin Sudirohusodo Makassar. Sampel pada penelitian ini adalah penderita stroke iskemik dan stroke hemoragik yang memenuhi kriteria inkluisi dari populasi yang ada. Besar sampel yang digunakan adalah 30 sampel (15 penderita stroke iskemik dan 15 penderita stroke hemoragik) dengan kriteria sampel :

a. Kriteria Inklusi

Penderita stroke iskemik, penderita stroke hemoragik dan penderita yang bersedia menjadi subjek penelitian b. Kriteria Ekslusi

Transient Ischemic Attacks, penderita yang tidak bersedia menjadi subjek penelitian

Teknik Pengambilan Sampel

Pengambilan sampel yang

dilakukan dengan tehnik quota sampling yaitu teknik non random sampling dimana peneliti menentukan jumlah sampel dengan cara menetapkan ciri-ciri khusus yang sesuai dengan kriteria inkluisi pada penelitian ini sehingga diharapkan peneliti dapat mengetahui gambaran nilai hasil indeks eritrosit antara penderita stroke iskemik dan penderita stroke hemoragik.

Pengumpulan Data

Prinsip kerja alat Hematologi Analyzer dengan pengukuran dan penyerapan sinar akibat interaksi sinar yang memepunyai panjang gelombang tertentu dengan larutan atau sampel yang dilewatinya. Prinsip impedansi aliran listrik berdasarkan pada variasi impedansi yang dihasilkan oleh sel-sel darah didalam mikropipet (celah chaber mikro) yang mana sampel darah yang diencerkan dengan elektrolit diluents akan melalui mikroaperture yang dipasangi dua elektroda (Anonim, 2016).

Alat digunakan yaitu tabung sampel, Hematology Analyzer, kapas alkohol, spoit dan tourniquet sedangkan bahan sampel Whole blood (darah lengkap). Reagen ABX Diluent, digunakan pada proses perhitungan sel darah dan hitung jenis sel. ABX Alphalhyse, ABX Biolyse, digunakan untuk melisiskan sel-sel darah dan menentukan konsentrasi hemoglobin. ABX Cleaner, digunakan sebagai bahan pembersih. 
Prosedur Kerja

Pra Analitik

Persiapan sampel: Sampel darah EDTA sebaiknya tes dilakukan segera selambatnya 2 jam. Sampel dapat disimpan sampai 24 jam di kulkas dengan suhu $4^{\circ} \mathrm{C}$

Analitik

Menjalankan darah control

Dipastikan alat dalam status ready, kemudian tekan tombol select.Ditekan tombol (2) untuk memilih '’2. Quality control', Pada layar QC, ditekan tombol (Sampel Now). Untuk memilih nomor file (Cl) yang dikehendaki, kemudian ditekan tombol (Enter). Selanjutnya ditekan tombol (1) untuk memilih 1. QC A Analyze dan layar Control Analysis akan tampil

Dihomogenisasikan darah control yang akan di periksa dengan baik. Dibuka tutupnya dan diletakkan di bawah Aspiration Probe. Dipastikan ujung Probe menyentuh dasar botol darah control agar tidak menghisap udara.

Ditekan Start Switch untuk memulai proses. Ditarik botol darah control dari bawah Probe setelah terdengar bunyi Beep dua kali. Setelah hasil tertampil pada layar, ditekan tombol [1] untuk menyimpan atau [2] untuk menolak hasil control tersebut. Kemudian ditekan tombol [3] untuk memilih "3.Print" agar hasil darah control tercetak.(Wulandari, 2017)

1. Menjalankan Mode whole Blood (WB)

Dipastikan alat dalam status Ready. Jika system tidak ada pada Whole Blood Mode, ditekan tombol [Mode] untuk merubah Analysis Mode dan digunakan tombol [Left]/[Right] untuk memilih "Whole
Blood (WB)", kemudian ditekan tombol [Enter].

Ditekan tombol [Sample No.] untuk memasukkan nomor identitas darah sample, kemudian ditekan tombol [Enter]. Dihomogenisasikan darah control yang akan diperiksa dengan baik. Dibuka tutupnya dan diletakkan di bawah Aspiration Probe. Dipastikan ujung Probe menyentuh dasar botol darah sampel agar tidak menghisap udara. Ditekan Start Switch untuk memulai proses. Ditarik Botol darah sampel dari bawah probe setelah terdengar bunyi Beep dua kali. Hasil akan tertampil pada layar dan secara otomatis tercetak pada kertas printer

Mematikan alat

Dipastikan alat dalam status Ready, kemudian ditekan tombol [Shutdown]. Diletakkan Cellclean di bawah Aspiration Probe, kemudian ditekan Start Switch untuk memulai proses. Ditarik Botol Cellclean dari bawah probe setelah terdengar bunyi Beep dua kali. Proses ini memakan waktu 5 menit. Setelah itu dimatikan alat setelah pesan "Turn offF the Power" tampil. (Anonim, 2016)

Pasca Analitik

Interpretasi hasil

Untuk Laki-laki yaitu Hemoglobin: 42-52 \%, Hematokrit: 14-18 g/dl, Jumlah Eritrosit : :4,76,1 juta/ml, MCV: 80-96 Fl, MCH: 27,5-33,2 pg, MCHC, : 32-36 g/dl sedangkan perempuan : Hemoglobin: 37-47 \%, Hematokrit : $12-16 \mathrm{~g} / \mathrm{dl}$, Jumlah Eritrosit :4,2-5,4 juta/ml, MCV: 80-96 fL, MCH: 27,5-33,2 pg, MCHC: $32-36 \mathrm{~g} / \mathrm{dl}$

Analisa data dilakukan secara deskriptif dan analitik. yang ditampilkan dalam tabel kemudian dibahas secara narasi. 


\section{HASIL}

Berdasarkan data yang diperoleh dengan melakukan uji laboratorium di bagian Laboratorium Hematologi Rumah Sakit dr. Wahidin Sudirohusodo pada bulan Maret sampai dengan Mei 2018. Sampel yang diambil berjumlah 30 sampel yang telah memenuhi kriteria inkluisi dan kriteria ekskluisi. Kemudian dilakukan pemeriksaan indeks eritrosit menggunakan alat hematologi analyzer diperoleh hasil sebagai berikut :

Tabel 1 Hasil Penentuan Indeks Eritrosit Penderita Stroke Iskemik

\begin{tabular}{|c|c|c|c|c|c|c|c|}
\hline \multirow[t]{2}{*}{ NO. } & \multirow{2}{*}{$\begin{array}{c}\text { Kode } \\
\text { Sampel }\end{array}$} & \multicolumn{6}{|c|}{ Parameter Pemeriksaan } \\
\hline & & $\begin{array}{c}\mathbf{H B} \\
\text { (gr/dl) }\end{array}$ & $\begin{array}{c}\text { HCT } \\
(\%)\end{array}$ & $\begin{array}{c}\text { RBC } \\
\left(10^{3} / \mathrm{mm}^{3}\right)\end{array}$ & $\begin{array}{c}\text { MCV } \\
\text { (fl) }\end{array}$ & $\begin{array}{c}\mathrm{MCH} \\
\text { (pg) }\end{array}$ & $\begin{array}{c}\text { MCHC } \\
(\%)\end{array}$ \\
\hline 1. & A1 & 9.7 & 29.3 & 29.2 & 96 & 33.2 & 33.1 \\
\hline 2. & A2 & 10.2 & 33.5 & 4.03 & 83.1 & 25.3 & 30.4 \\
\hline 3. & A3 & 13.2 & 37.6 & 4.89 & 76.9 & 27.0 & 35.1 \\
\hline 4. & A4 & 11.5 & 38.9 & 4.04 & 96.3 & 28.5 & 29.6 \\
\hline 5. & A5 & 12.3 & 40 & 4.48 & 89 & 28 & 31 \\
\hline 6. & A6 & 10.6 & 34 & 3.80 & 89 & 28 & 31 \\
\hline 7. & A7 & 19.1 & 59.2 & 5.63 & 87 & 33.9 & 32.3 \\
\hline 8. & A8 & 11.7 & 37 & 4.78 & 78 & 25 & 31 \\
\hline 9. & A9 & 10.5 & 36 & 5.24 & 69 & 20 & 29 \\
\hline 10. & A10 & 11.1 & 33 & 3.84 & 85 & 29 & 34 \\
\hline 11. & A11 & 11.7 & 34.9 & 4.3 & 89 & 30.1 & 33.7 \\
\hline 12. & A12 & 10.7 & 35.0 & 4.00 & 88 & 26.7 & 30.4 \\
\hline 13. & A13 & 15.4 & 45.5 & 5.79 & 79.3 & 26.8 & 33.8 \\
\hline 14. & A14 & 10.6 & 34.5 & 3.77 & 91,5 & 28,1 & 30,7 \\
\hline 15. & A15 & 13.9 & 42.8 & 5.61 & 76.3 & 24.8 & 32.5 \\
\hline
\end{tabular}

Sumber : Data Primer 2018

Tabel 2 Hasil Penentuan Indeks Eritrosit Penderita Stroke Hemoragik

\begin{tabular}{|c|c|c|c|c|c|c|c|}
\hline \multirow[t]{2}{*}{ No. } & \multirow{2}{*}{$\begin{array}{c}\text { Kode } \\
\text { Sampel }\end{array}$} & \multicolumn{6}{|c|}{ Parameter Pemeriksaan } \\
\hline & & $\begin{array}{c}\text { HB } \\
\text { (gr/dl) }\end{array}$ & $\begin{array}{c}\text { HCT } \\
(\%)\end{array}$ & $\begin{array}{c}\text { RBC } \\
\left(10^{3} / \mathbf{m m}^{3}\right)\end{array}$ & $\begin{array}{c}\text { MCV } \\
\text { (fl) }\end{array}$ & $\begin{array}{c}\text { MCH } \\
\text { (pg) }\end{array}$ & $\begin{array}{c}\text { MCHC } \\
(\%)\end{array}$ \\
\hline 1. & B1 & 15,9 & 53 & 6.4 & 88 & 26 & 30 \\
\hline 2. & $\mathrm{~B} 2$ & 10,6 & 37 & 3.84 & 96 & 28 & 29 \\
\hline 3. & B3 & 17.6 & 54.2 & 6.74 & 79.3 & 26.1 & 32.4 \\
\hline 4. & B4 & 15,5 & 50,6 & 5,23 & 96 & 29.6 & 30.6 \\
\hline 5. & B5 & 8,5 & 28,7 & 3.26 & 88.0 & 26.1 & 29.6 \\
\hline 6. & B6 & 12,6 & 40.6 & 4.70 & 86,4 & 26.8 & 31.0 \\
\hline 7. & B7 & 14.7 & 47.7 & 5.18 & 92.1 & 28.4 & 30.8 \\
\hline 8. & B8 & 7,9 & 25.1 & 2,99 & 83.9 & 26.4 & 31.5 \\
\hline 9. & B9 & 10.1 & 32 & 3.49 & 91 & 29 & 32 \\
\hline 10. & B10 & 18.3 & 52 & 6.15 & 84 & 30 & 36 \\
\hline 11. & B11 & 18 & 57 & 6.06 & 94 & 30 & 32 \\
\hline
\end{tabular}


Jurnal Media Analis Kesehatan, Vol. 9, No.2, November 2018

http://journal.poltekkes-mks.ac.id/ojs2/index.php/mediaanalis

e-ISSN : 2621-9557

p-ISSN : 2087-1333

\begin{tabular}{cccccccc}
\hline 12. & B12 & 16.1 & $49 . .5$ & 5.65 & 87.6 & 28.5 & 32.5 \\
\hline 13. & B13 & 9.3 & 29.5 & 3.35 & 88.1 & 27.8 & 31.5 \\
\hline 14. & B14 & 9.5 & 28.5 & 3.40 & 84 & 27.9 & 33.2 \\
\hline 15. & B15 & 10.8 & 32.9 & 3.53 & 92.3 & 30.6 & 32.8 \\
\hline
\end{tabular}

Sumber : Data Primer 2018

Tabel 3 Distribusi Penyakit Stroke Iskemik Menurut Hasil Nilai HB, HCT, RBC, MCV, MCH Dan MCHC

\section{RENDAH TINGGI NORMAL}

\begin{tabular}{cccc}
\hline RBC & 4 & 0 & 11 \\
\hline HB & 10 & 1 & 4 \\
\hline HCT & 8 & 1 & 6 \\
\hline MCV & 5 & 0 & 10 \\
\hline MCH & 6 & 0 & 9 \\
\hline MCHC & 8 & 0 & 7
\end{tabular}

Sumber : Data Primer 2018

Berdasarkan tabel 3 diperoleh data bahwa pasien stroke iskemik dengan nilai RBC (normal 11 orang dan rendah 4 orang), nilai HB (normal 4 orang, tinggi 1 orang, dan rendah 10 orang), nilai HCT (normal 6 orang, tinggi 1 dan rendah 8 orang), nilai MCV (normal 10 orang dan rendah 5 orang), nilai $\mathrm{MCH}$ (normal 9 orang dan rendah 6 orang), nilai $\mathrm{MCHC}$ (normal 7 orang dan rendah 8 orang)

Tabel 4 Distribusi Penyakit Stroke Hemoragik Menurut Hasil Nilai HB, HCT, RBC, MCV, MCH Dan MCHC

\begin{tabular}{cccc}
\hline & RENDAH & TINGGI & NORMAL \\
\hline RBC & 7 & 2 & 6 \\
HB & 7 & 3 & 5 \\
\hline HCT & 6 & 5 & 4 \\
\hline MCV & 1 & 0 & 14 \\
\hline MCH & 5 & 0 & 10 \\
\hline MCHC & 8 & 0 & 7
\end{tabular}

Sumber : Data Primer 2018

Berdasarkan tabel 4 diperoleh data bahwa pasien stroke hemoragik dengan nilai RBC (normal 6 orang, tinggi 2 orang dan rendah 7 orang), nilai HB (normal 5 orang, tinggi 3 orang, dan rendah 7 orang), nilai HCT ( normal 4 orang, tinggi 5 dan rendah 6 orang), nilai MCV (normal 14 orang dan tinggi 1 orang), nilai $\mathrm{MCH}$ (normal 10 orang dan rendah 5 orang), nilai MCHC (normal 7 orang dan rendah 8 orang) 
Jurnal Media Analis Kesehatan, Vol. 9, No.2, November 2018

http://journal.poltekkes-mks.ac.id/ojs2/index.php/mediaanalis

e-ISSN : 2621-9557

p-ISSN : 2087-1333

Tabel 5 Prevalensi Rasio Penyakit Stroke Iskemik Dan Stroke Iskemik Menurut Nilai MCV

\begin{tabular}{cccc}
\hline \multirow{2}{*}{ Sampel } & \multicolumn{2}{c}{ Frekuuensi Pada } & Jumlah \\
\cline { 2 - 3 } & Stroke Iskemik & Stroke Hemoragik & Sampel \\
\hline MCV Rendah & 5 & 1 & 6 \\
\hline MCV Normal & 10 & 14 & 24 \\
\hline Jumlah & 15 & 15 & 30 \\
\hline
\end{tabular}

Sumber : Data Primer 2018

Dari tabel kontigensi $2 \times 2$ dapat dihitung besar rasio prevalensi :

$$
\begin{aligned}
\mathrm{RP}=\mathrm{a} / & (\mathrm{a}+\mathrm{b}): \mathrm{c} /(\mathrm{c}+\mathrm{d}) \\
& =5 /(5+1): 10 /(10+14) \\
& =5 / 6: 10 / 24 \\
& =0,83: 0,45 \\
& =1,84
\end{aligned}
$$

Rasio Prevalensi $(\mathrm{RP})=1,84$ atau $>1$ artinya ada dugaan adanya factor risiko nilai $\mathrm{MCV}$ rendah terhadap efek sakit memang benar.

$$
\begin{aligned}
& \text { Odds Rasio } \\
& \begin{aligned}
& \mathrm{OR}=\mathrm{ad} / \mathrm{bc} \\
&=5.14 / 1.10 \\
&=70 / 10 \\
&=7
\end{aligned}
\end{aligned}
$$

Odds Rasio $(\mathrm{OR})=7$ berarti pasien yang mempunyai nilai MCV rendah lebih beresiko menderita stroke iskemik dan stroke hemoragik 7 kali lebih besar dari pada yang mempunyai nilai MCV normal

Tabel 6 Prevalensi Rasio Penyakit Stroke Iskemik Dan Stroke Iskemik Menurut Nilai MCH

\begin{tabular}{cccc}
\hline & \multicolumn{2}{c}{ Frekuuensi Pada } & Jumlah \\
\cline { 2 - 3 } Sampel & Stroke Iskemik & Stroke Hemoragik & Sampel \\
\hline MCH Rendah & 6 & 5 & 11 \\
\hline MCH Normal & 9 & 10 & 19 \\
\hline Jumlah & 15 & 15 & 30 \\
\hline
\end{tabular}

Sumber : Data Primer 2018

Dari tabel kontigensi $2 \times 2$ dapat dihitung besar rasio prevalensi :

$$
\begin{aligned}
\mathrm{RP}=\mathrm{a} / & (\mathrm{a}+\mathrm{b}): \mathrm{c} /(\mathrm{c}+\mathrm{d}) \\
& =6 /(6+5): 9 /(9+10) \\
& =5 / 11: 9 / 19 \\
& =0,45: 0,47 \\
& =0,95
\end{aligned}
$$

Rasio Prevalensi $(\mathrm{RP})=0,95$ atau $<1$ artinya ada dugaan tidak adanya factor risiko nilai $\mathrm{MCH}$ rendah terhadap efek sakit.
Odds Rasio

$\mathrm{OR}=\mathrm{ad} / \mathrm{bc}$

$$
\begin{aligned}
& =6.10 / 5.9 \\
& =60 / 45 \\
& =1,333
\end{aligned}
$$

Odds Rasio $(\mathrm{OR})=1.333$ berarti pasien yang mempunyai nilai $\mathrm{MCH}$ rendah lebih beresiko menderita stroke iskemik dan stroke hemoragik 1.333 kali lebih besar daripada yang mempunyai nilai $\mathrm{MCH}$ normal.

Tabel 7 Prevalensi Rasio Penyakit Stroke Iskemik Dan Stroke Iskemik Menurut Nilai MCHC 


\begin{tabular}{cccc}
\hline & \multicolumn{2}{c}{ Frekuuensi Pada } & Jumlah \\
\cline { 2 - 3 } Sampel & Stroke Iskemik & Stroke Hemoragik & Sampel \\
\hline MCHC Rendah & 8 & 8 & 16 \\
\hline MCHC Normal & 7 & 7 & 14 \\
\hline Jumlah & 15 & 15 & 30 \\
\hline
\end{tabular}

Sumber : Data Primer 2018

Dari tabel kontigensi $2 \times 2$ dapat dihitung besar rasio prevalensi :

$$
\begin{aligned}
\mathrm{RP} & =\mathrm{a} /(\mathrm{a}+\mathrm{b}): \mathrm{c} /(\mathrm{c}+\mathrm{d}) \\
& =8 /(8+8): 7 /(7+7) \\
& =8 / 16: 7 / 14 \\
& =0,5: 0,5 \\
& =1
\end{aligned}
$$

Rasio Prevalensi $(\mathrm{RP})=1$ artinya factor resiko bersifat netral, factor resiko nilai $\mathrm{MCHC}$ rendah beresiko terhadap stroke iskemik sama besar dengan factor resiko nilai $\mathrm{MCHC}$ rendah terhadap stroke hemoragik

\section{PEMBAHASAN}

Penelitian ini dilakukan untuk mengetahui gambaran nilai indeks eritrosit pada penderita stroke iskemik dan stroke hemoragik. Hasil yang diperoleh dari penelitian yang dilakukan di Laboratorium RSUP Dr. Wahidin Sudirohhusodo gambaran nilai indeks eritrosit pada pasien stroke iskemik dan stroke hemoragik menunjukkan nilai $\mathrm{MCV}, \mathrm{MCH}$ dan MCHC yang rendah beresiko lebih besar terjadinya stroke.

Penyakit stroke iskemik dan stroke hemoragik merupakan suatu kondisi yang berlawanan. Pada stroke iskemik terjadi gangguan ketersediaan darah pada suatu area diotak dengan kebutuhan oksigen dan nutrisi diarea tersebut, sedangkan pada stroke hemoragik cranium yang tertutup mengandung darah yang terlalu banyak.

$$
\begin{aligned}
& \text { Odds Rasio } \\
& \begin{aligned}
& \mathrm{OR}=\mathrm{ad} / \mathrm{bc} \\
&=8.7 / 8.7 \\
&=56 / 56 \\
&=1
\end{aligned}
\end{aligned}
$$

Odds Rasio $(\mathrm{OR})=1$ berarti bersifat netral dimana pasien yang mempunyai nilai MCHC rendah sama- sama beresiko 1 kali lebih besar menderita stroke iskemik dan stroke hemoragik daripada yang mempunyai nilai MCHC normal.

Kadar Hemoglobin merupakan factor yang memberikan konstribusi independen terhadap ukuran infark bersama dengan beberapa factor lain seperti umur, jenis kelamin, kadar glukosa saat masuk rumah sakit dan subtype stroke. Semakin luas daerah infark maka akan berhubungan dengann semakin buruknya derajat klinis penyakit sroke. Kekurangan oksigen akan menyebabkan asidosis dan selanjutnya menyebabkan gangguan fungsi enzim-enzim karena tingginya ion $\mathrm{H}$. Selanjutnya asidosis menimbulkan edema cerebral yang ditandai pembengkakan sel, terutama jaingan glia, dan berakibat terhadap sirkulasi. Oleh karena itu terjadi peningkatan resistensi vaskuler Dn kemudian penurunan dari perfusi sehingga terjadinya perluasan daerah stroke.

Pada penelitian ini ditemukan bahwa pasien stroke umumnya terjadi pada laki-laki. Laki-laki beresiko 
Jurnal Media Analis Kesehatan, Vol. 9, No.2, November 2018

http://journal.poltekkes-mks.ac.id/ojs2/index.php/mediaanalis

e-ISSN : 2621-9557

p-ISSN : 2087-1333

terkena stroke karena tedapat factor lain seperti kebiasaan merokok. Asap rokok mengandung berbagai bahan seperti nikotin, Carbon Monoxide (CO). Carbon Monoxide memiliki kecenderungan yang kuat untuk berikatan dengan hemoglobin dalam sel-sel darah merah. ikatan ini 210300 kali lebih kuat daripada ikatan hemoglobin dengan oksigen.

Seharusnya, hemoglobin ini berikatan dengan oksigen yang sangat perting untuk pernapasan sel-sel tubuh, tetapi karena gas $\mathrm{CO}$ lebih kuat daripada oksigen, maka hemoglobin berikatan dengan $\mathrm{CO}$. Kadar gas $\mathrm{CO}$ menimbulkan desaturasi hemoglobin, menurunkan langsung persediaan oksigen untuk jaringan seluruh tubuh termasuk miokard. Carbon Monoxide menggantikan tempat oksigen di hemoglobin, menggangu pelepasan oksigen dan mempercepat aterosklerosis (pengapuran / penebalan dinding pembuluh darah). Dengan demikian, CO menurunkan kapasitas latihan fisik, meningkatkan viskositas darah, sehingga mempermudah penggupalan darah.

Dalam penentuan anemia, Hct dan Rbc juga bisa dikatakan sebagai kriteria anemia walaupun $\mathrm{Hb}$ yang dianggap paling akurat karena memberikan gambaran langsung kemampuan sel darah merah mengikat oksigen. Kehilangan suplai oksigen secara mendadak kejaringan otak selain glukosa merupakan langkah pertama dan utama dalam pathogenesis stroke iskemik.

Keadaaan darah merupakan salah satu factor risiko stroke. Viskositas darah yang meningkat karena kadar hematokrit yang meningkat menyebabkan aliran darah ke otak lebih lambat. Selain itu kadar
Het sangat dinamis karena dipengaruhi oleh kondisi hemodinamik, misalnya saat seseorang dalam keadaan dehidrasi maka Hctnya cenderung meningkat dan setelah direhidrasi maka kadar Hctnya bisa menurun. Keadaan hemodinamik merupakan gangguan pada tubuh baik aliran darah maupun keseimbangan cairan tubuh yang dapat menimbulkan terjadinya infark.

Penelitian yang dilakukan ditemukan diagnose disertai dengan penyakit Hipertensi. Hipertensi atau tekanan darah tinggi adalah suatu gangguan pada pembuluh darah yang mengakibatkan suplai oksigen dan nutrisi yang dibawa oleh darah, terhambat sampai ke jaringan tubuh yang membutuhkannya. Pada penelitian ini hipertensi cenderung menyebabkan stroke iskemik.

Tekanan darah tinggi atau Hipertensi dapat mempercepat pengerasan dinding pembuluh darah arteri dan mengakibatkan penghancuran lemak pada sel otot polos sehingga dapat mempercepat proses aterosklerosis melalui efek penekanan pada lapisan dalam dinding arteri yang berakibat pembentukan plak pembuluh darah semakin cepat.Penelitian ini sejalan dengan peneletian yang dilakukan Alfica Agus (2015) yang menyatakan bahwa terdapat hubungan antara hipertensi dengan kejadian stroke. Hipertensi mempunyai resiko terkena stroke lebih besar dibandingkan tidak hipertensi

Dari analisa data yang dilakukan dengan perhitungan Odds Rasio dengan nilai OR $(<1$ bersifat protektif, $>1$ bersifat beresiko, dan = 1 bersifat netral, risiko kelompok terpajan sama dengan kelompok tidak 
Jurnal Media Analis Kesehatan, Vol. 9, No.2, November 2018

http://journal.poltekkes-mks.ac.id/ojs2/index.php/mediaanalis

e-ISSN : 2621-9557

p-ISSN : 2087-1333

terpajan). Untuk nilai MCV dari perhitungan Odds Rasio di dapatkan hasil 7. Resiko terserang stroke iskemik dan hemoragik 7 kali lebih besar pada orang yang nilai MCV nya rendah dibandingkan dengan orang yang nilai MCV nya normal. Untuk nilai $\mathrm{MCH}$ dari perhitungan Odds Rasio didapatkan hasil yaitu 1,333 yang berarti resiko terserang stroke iskemik dan hemoeagik 1,333 kali lebih besar pada orang yang nilai MCH nya rendah dibandingkan dengan orang yang nilai $\mathrm{MCH}$ nya normal. Sedangkan nilai MCHC dari perhitungan Odds Rasio didapatkan hasil yaitu 1 yang berarti resiko terserang stroke iskemik dan stroke hemoragik 1 kali lebih besar pada orang yang nilai $\mathrm{MCH}$ nya rendah dibandingkan dengan orang yang nilai MCH nya normal.

Berdasarkan hasil yang diperoleh dari penelitian yang dilakukan dinyatakan bahwa gambaran nilai indeks eritrosit pada penderita stroke iskemik dan stroke hemoragik menunjukkan nilai rendah pada nilai $\mathrm{MCV} \mathrm{MCH}$, dan $\mathrm{MCHC}$.

\section{KESIMPULAN}

Berdasarkan penelitian yang telah dilakukan didapatkan gambaran hasil Index Eritrosoit pada penderita stroke iskemik terdapat 5 penderita dengan nilai MCV rendah, 6 penderita dengan nilai $\mathrm{MCH}$ rendah dan 8 penderita dengan dilai MCHC rendah dan pada penderita stroke hemoragik terdapat 1 penderita dengan nilai MCV rendah, 5 penderita dengan nilai $\mathrm{MCH}$ rendah dan 8 penderita dengan dilai MCHC rendah

\section{SARAN}

Bagi masyarakat, perlu diberikan penyuluhan mengenai gaya hidup sehat terutama factor yang dapat menyebababkan stroke iskemik dan stroke hemoragik, serta melakukan pemeriksaan pada layanan kesehatan terdekat.

\section{DAFTAR PUSTAKA}

Adhim M.2013.Hubungan Antara Kadar Hematokrit Dengan Kejadian Stroke Iskemik Di RSUD Dr. Moewardi. Disertai tidak diterbitkan.Surakarta: Fakultas Kedokteran Universitas Muhammadiyah Surakarta

Anonim,2016.http://www.academia. edu/24984008/2016/Hematol ogy_Analyzerdiakses 14 Desember 2017

Anonim,2017.https://biohasanah.wor dpres.com/2016/darah-dansistemperedaran -darah pada-manusia/,diakses 30 November 2017

Bakta,Made.2014.Hematologi Klinik Ringkas.Jakarta : Buku Kedokteran EGC

Bustan M.N.2007.Epidemielogi Penyakit Tidak Menular. Jakarta : PT Rineka Cipta

Basir,Hasmawaty.;Kaelan,Cahyono.; Aliah A. 2014.Hubungan Kadar Hemoglobin, Hematokrit dan Eritrosit pada Penderita Stroke Iskemik. Disertai tidak diterbitkan. Makassar: Fakultas Kedokteran Universitas Hasanuddin

Dinas Kesehatan Provinsi Sulawesi Selatan.2015.Profil

Kesehatan Provinsi Sulwesi Selatan Tahun 2014. Makassar 
Jurnal Media Analis Kesehatan, Vol. 9, No.2, November 2018

http://journal.poltekkes-mks.ac.id/ojs2/index.php/mediaanalis

e-ISSN : 2621-9557

p-ISSN : 2087-1333

http://www.depkes.go.id/PR

OFIL_KES_PROVINSI_201

4, diakses 29 November 2017.

Feigin,Valery.2009.STROKE.Jakarta

: PT Bhuana Ilmu Populer

Hoffbrand,A.;Moss P.2013.Kapita

Selekta Hematologi.Jakarta :

Buku Kedoteran EGC

Holistic Health Solution.2011.Stroke

Di Usia Muda.Jakarta :

Grasindo

IndrawatiL.;Sari

W.;Dewi

S.,2016.Stroke Cegah Dan

Obati Sendiri.Jakarta Timur :

Penerbit Plus

Hardjoeno,H.2003.Interpretasi Hasil

Tes Laboratorium

Diagnostik.Makassar

Lembaga Penerbit Universitas Hasanuddin

Kalma, Herman, NaimN, Bakhri S.2016.Panduan Penulisan Skripsi. Disertai tidak diterbitkan.Makassar : Analis Kesehatan

Kee,Joyce L. 2013. Pedoman Pemriksaan Laboratorium Dan Diagnostik.Jakarta : Buku Kedokteran EGC

Kiswari,R.2014.Hematologi dan Transfusi.Jakarta : Erlangga

L,Tao.K,Kndall.2014.Sinopsi Organ System Hematologi Dan Onkologi. Tangerang : Karisma Publishing Group

McPhee,Stephen J.;Ganong,William F.2011.Patofisiologi Penyakit Pengantar Menuju Kedokteran Klinis.Jakarta : Buku Kedokteran EGC

Pratiwi,Indah P.2017.Analisis Kadar Hemoglobin, Hematokrit dan Jumlah Trombosit Sebelum dan Sesudah Pemberian Infus pada Penderita Demam Berdarah Dengue di RSUD
Syekh Yusuf

Kab.Gowa.Disertai tidak

diterbitkan. Makassar : Analis

Kesehatan

Price,Sylvia A.;Wilson,Lorraine

M.2014.Patofisiologi Konsep

Klinis Proses-Proses

Penyakit. Jakarta : Buku

Kedokteran EGC

Pusparani,S.2009.Hubungan Antara

Hipertensi Dan Stroke

Hemoragik Pada

Pemeriksaan CT-Scan Kepala

Di Instalasi Radiologi RSUD

Dr. Moewardi Surakarta

Sacher,Ronal A.;McPherson,Richard

A.2004.Tinjauan Klinis Hasil

Pemeriksaan

Laboratorium.Jakarta : Buku

Kedokteran EGC

Sadikin,Mohammad.2013.Biokimia

Darah.Jakarta : Widya

Medika

Sudewo B.2009.Hidup Sehat Cara Mas Dewo.Jakarta : PT Agro Media Pustaka

Sudiono,Herawati.;Iskandar.;Edward H.;Halim L.;Santoso R.2009.

Penuntun Patologi Klinik Hematologi.Ukrida : Biro Publikasi Fakultas

Kedokteran Ukrida

Tartowo; Wartonah.2008.Keperawata $n$ Medikal Bedah Gangguan Sistem Hematologi. Jakarta Timur : Trans Info Media

Triasti,A.P.2016.Faktor-Faktor Yang Mempengaruhi Fungsi Kognitif Penderita Stroke Non Hemoragik.Semarang

Fakultas Kedokteran

Universitas Diponegoro

Wahyu,Genis G.2009.Stroke Hanya Menyerang Orang Tua.Yogyakarta : Penerbit B First. 